\title{
Adaptive servo-ventilation in patients with chronic heart failure and sleep disordered breathing: predictors of usage
}

\author{
Leonie Kolb ${ }^{1} \cdot$ Michael Arzt ${ }^{1} \cdot$ Stefan Stadler ${ }^{1} \cdot$ Katharina Heider $^{1} \cdot$ Lars S. Maier $^{1} \cdot$ Maximilian Malfertheiner $^{1}$
}

Received: 26 March 2020 / Revised: 10 July 2020 / Accepted: 21 August 2020 / Published online: 3 September 2020

(C) The Author(s) 2020

\begin{abstract}
Purpose Adaptive servo-ventilation (ASV) is a therapy designed for patients with central sleep apnea (CSA) and Cheyne Stokes respiration. The aim of this study was to find predictors of ASV usage in patients with CSA in a routine sleep clinic cohort. Methods In this retrospective study, consecutive patients in whom ASV therapy was initiated at the University Hospital Regensburg between 2011 and 2015, were analyzed. Analysis included polysomnographies of diagnostic and ASV initiation nights, a phone questionnaire on ASV usage, readout of the ASV device 1 month after initiation ("early ASV usage," 1 month after ASV initiation), and the readout of the last month before a reappointment date set in 2015 ("late ASV usage," median 17 months after ASV initiation).

Results In 69 consecutive patients, the mean early and late ASV usage per night was $4.8 \pm 2.5 \mathrm{~h}$ and $4.1 \pm 3.0 \mathrm{~h}$, respectively. Seventeen months after initiation, $57 \%$ of patients used the device $\geq 4 \mathrm{~h}$ per night, and of those $91 \%$ reported a subjective benefit from ASV therapy. Early ASV usage was significantly associated with late ASV usage (univariable regression: Beta $0.8,95 \% \mathrm{CI}$ $[0.6 ; 1.0] p<0.001)$. In multivariable regression analysis, short duration of slow wave sleep (N3) during diagnostic polysomnography (Beta $-6.2,95 \% \mathrm{CI}[-11.0 ;-1.5] ; p=0.011$ ) and subjective benefit from ASV (Beta $174.0,95 \% \mathrm{CI}$ $[68.6 ; 279.5] ; p=0.002$ ) were significantly associated with longer late ASV usage.

Conclusion Early ASV usage predicts late ASV usage. In addition, low slow wave sleep before ASV initiation and subjective benefit from ASV may contribute to higher late ASV usage.
\end{abstract}

Keywords Central sleep apnea $\cdot$ Adaptive servo-ventilation $\cdot$ Usage $\cdot$ Adherence $\cdot$ Cheyne Stokes respiration $\cdot$ Sleep stages

\section{Introduction}

Positive airway pressure therapies such as continuous positive airway pressure (CPAP) and adaptive servo-ventilation (ASV) are important treatments of various forms of sleep disordered breathing (SDB). ASV was designed for patients with central sleep apnea (CSA) and Cheyne Stokes respiration (CSR) [1-3] and is also effective in patients with other types of CSA [4-6]. Since the results of the SERVE-HF trial

Electronic supplementary material The online version of this article (https://doi.org/10.1007/s11325-020-02182-2) contains supplementary material, which is available to authorized users.

Michael Arzt

michael.arzt@ukr.de

1 Department of Internal Medicine II, Cardiology and Pneumology, Center for Sleep Medicine, University Medical Center Regensburg, Regensburg, Germany became public in 2015, showing an increased risk for cardiovascular mortality in the ASV-treated group of patients with chronic heart failure and reduced ejection fraction (HFrEF, EF $\leq 45 \%$ ), NYHA class II-IV, and predominant CSA [5-8], ASV is contraindicated in this specific patient population [5-7]. However, most of the patients who are treated with ASV in routine clinical care have severe CSA and treatment emergent CSA and a history of heart failure with preserved ejection fraction (HFpEF) [4]. The subgroup in which ASV is contraindicated is small [4], and ASV is still recommended for the treatment of CSA. Recommendations are based on the findings that in patients with CSA, ASV is more efficient in suppressing central apneas and hypopneas $[1,5,7,9,10]$. An improvement in quality of life, sleep quality, cardiopulmonary efficiency, and a reduction of elevated natriuretic peptides under ASV therapy were also reported [5, 7, 9, 11-13].

Previous studies support that longer usage of PAP therapy leads to better therapy success [13-15]. For example, longer CPAP usage is associated with improved blood pressure 
control [15-17] as well as cognitive functions [17, 18]. In most ASV and CPAP studies, sufficient therapy usage is considered to be a usage above $4 \mathrm{~h}$ per night [16, 18-23]. The usage of ASV therapy in the previous studies ranged between 3.7 and $5.2 \mathrm{~h}$ /night [9-11, 24-26]. Variables predicting usage behavior could be helpful to guide selection of patients for treatment and treatment indication as well as to support patients undergoing ASV initiation in their individual needs and thus optimize therapy usage.

Previous studies evaluating predictors of ASV compliance identified proactive patient management [25] and high early ASV usage as predictors [13] for high late ASV usage. Such studies were either limited by the lack of a full clinical data set [25] or by a specific oligosymptomatic study population of a long-term randomized controlled trial with control arm [13]. Thus, the aim of this study was to find predictors of ASV usage of patients with CSA in a routine sleep clinic cohort.

\section{Methods}

\section{Patients}

This retrospective, monocentric analysis included all consecutive patients, whom ASV therapy has been prescribed between 2011 and May 2015 at the Department of Internal Medicine II at the University Medical Center Regensburg. Exclusion criteria for this analysis were death before followup visit in 2015, inaccessible data on late therapy usage at the reappointment date 2015, and initiation of ASV therapy less than 2 months before the reappointment date (Fig. 1).

All patients were contacted between June and October 2015 to reassess the indication for ASV after publication of the results of the SERVE-HF results [8]. Indication for ASV included hypo- or normocapnic CSA in stable heart failure, primary CSA, and treatment emergent CSA. Patients with severe pulmonary disease were excluded. Some patients treated with ASV therapy had heart failure with reduced ejection fraction $(\leq 45 \%)$, NYHA class II-IV, and predominant CSA, referred to as "risk group" $[5,6,8]$. This analysis was approved by the Ethics Committee of the University of Regensburg (approval no. 15-101-0255) and was conducted in accordance with the principles of Good Clinical Practice and the Declaration of Helsinki.

\section{Baseline assessment}

Assessment included patient records of the first patient visit at the sleep laboratory, including patient characteristics, medication, comorbidities, Epworth sleepiness scale (ESS) score, echocardiography results, diagnostic polysomnography (PSG), and PSG of the ASV initiation night.

\section{Follow-up assessment}

At a follow-up visit in 2015 (median 17 months with an IQR of 16 months after therapy initiation), the usage of the ASV device 1 month after initiation ("early ASV usage") and of the last month before the reappointment date ("late ASV usage") were objectively assessed using the readout of the ASV devices. The 8 patients, who did not attend this last follow-up assessment, were known therapy dropouts before follow-up visit in 2015 with a mean late ASV usage of $0.0 \mathrm{~h}$ per day. Routine assessment included a questionnaire on subjective ASV usage behavior and subjective benefit from ASV. Subjective benefit was assessed on a dichotomous nominal scale: (1) "yes," if patients perceived ASV therapy beneficial,
Fig. 1 Patient flow chart. ASV adaptive servo-ventilation; numerical value: number of patients, follow-up visit: 2015 ; the total number of patients included in this analysis was 69

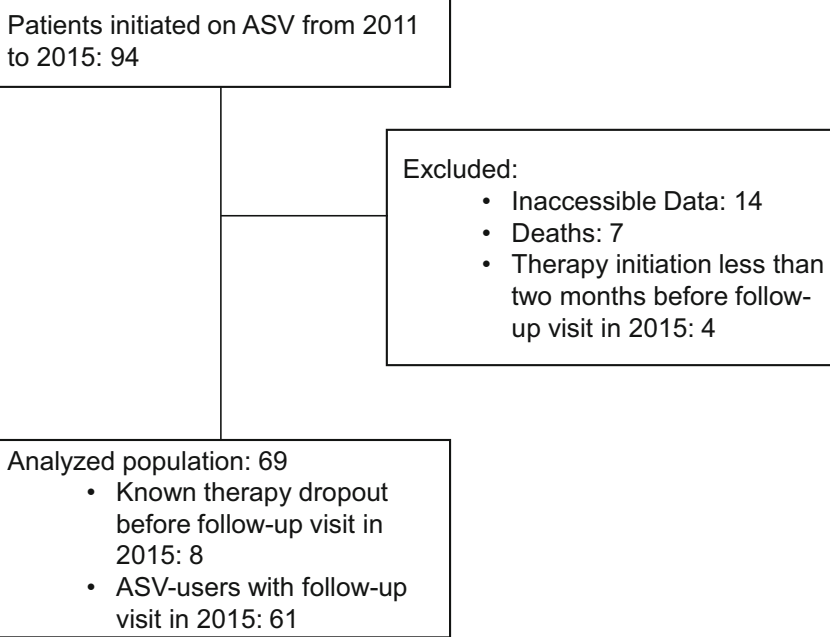

- Known therapy dropout before follow-up visit in 2015: 8

- ASV-users with follow-up visit in 2015: 61 
and (2) "no," if patients perceived ASV therapy non beneficial.

\section{Epworth sleepiness scale}

The ESS questionnaire is a validated questionnaire on daytime sleepiness. Scores range from 0 (least sleepy) to 24 (sleepiest). Excessive daytime sleepiness was defined as a score of 11 or higher [27].

\section{Polysomnography}

PSGs of diagnostic and ASV initiation nights were analyzed as prescribed previously $[4,28]$ according to routine standard criteria. Sleep and associated events were determined according to the American Academy of Sleep Medicine (AASM) Manual 2007 and the following updates [29-32]. The arousal index is the number of interruptions of sleep per hour of sleep. The oxygen desaturation index (ODI) was defined as the number of episodes with oxygen desaturation $\geq 4 \%$ per hour of sleep. Patients with a proportion of over $50 \%$ central apneas of total apneas (cAI/AI) were diagnosed with central sleep apnea (CSA). Periodic breathing pattern (Cheyne Stokes respiration-CSR) was diagnosed when both of the following conditions were fulfilled: (1) $\geq 3$ consecutive episodes of central apnea and/or hypopnea, separated by a crescendodecrescendo change in breathing amplitude with a cycle length of at least $40 \mathrm{~s}$ (typically lasting $45-90 \mathrm{~s}$ ) and (2) $\geq 5$ central apnea and/or hypopnea episodes per hour associated with the crescendo or decrescendo breathing pattern recorded over a minimum of $2 \mathrm{~h}$ of monitoring [30].

\section{Clinical definitions of central sleep apnea}

CSA was defined according to the ERS Task Force statements on central breathing disturbances during sleep [5] and the international classification of sleep disorders [33]. According to the clinical information available, patients were diagnosed with CSA in heart failure if they had HFrEF or HFpEF without documented opioid intake [5]. CSA in stroke was diagnosed with a preceding stroke being the best explanation for the occurrence of CSA. Definitions for treatment emergent CSA included (a) AHI $\geq 5 / \mathrm{h}$ and predominantly obstructive respiratory events in the diagnostic PSG; (b) significant resolution of obstructive events and emergence of persistent central events during positive airway pressure treatment with a central AHI of $\geq 5 / \mathrm{h}$ and $\geq 50 \%$ central events; and (c) the occurrence could not be better explained with another CSA disorder [5]. Drug-induced CSA was diagnosed when CSA occurred in the context of drugs that are known to induce CSA (such as opioids and baclofen). Primary CSA was diagnosed when none of the previously stated causes applied.

\section{Echocardiography}

Echocardiography was routinely performed in all patients prior to PSG to measure left ventricular systolic function and signs of relevant structural heart disease. In the context of the findings of the SERVE-HF trial [3, 8], patients with symptoms and/or signs of heart failure and left ventricular ejection fraction (LVEF) $\leq 45 \%$ were classified as HFrEF. Patients with LVEF > 45\%, symptoms, and/or signs of heart failure and signs of relevant structural heart disease (left atrial enlargement or diastolic dysfunction) were classified as HFpEF.

\section{Statistical analysis}

Patients were initially stratified into two groups according to late ASV usage: sufficient usage was defined as ASV usage $\geq$ $4 \mathrm{~h}$, whereas usage $<4 \mathrm{~h}$ was defined as insufficient usage. Continuous data are expressed as mean \pm standard deviation (SD), unless otherwise stated. To compare usage groups "usage $\geq 4 \mathrm{~h}$ " and "usage $<4 \mathrm{~h}$," continuous variables were compared using a two-sided $t$ test, whereas nominal variables were compared by using the chi-square test or, when the expected frequency was $<5$, the Fisher's exact test. For the comparison of diagnostic with ASV initiation night, paired $t$ test was used. Delta variables were defined to show the changes of various PSG parameters from diagnostic to ASV initiation night, with the value of the diagnostic night being subtracted from the value of the ASV initiation night. Univariable ANOVA was used to test the differences in the changes from both usage groups "usage $\geq 4 \mathrm{~h}$ " and "usage $<4$ h." To assess the effect of the parameters on late usage, uniand multivariable regression models were applied. A multivariable linear regression model, including all independent variables with $p<0.1$ in the univariable models, was calculated. In addition, the multivariable model accounted for age, sex, and BMI. A two-sided $p$ value $<0.05$ was considered statistically significant. Statistical analysis was performed using SPSS Statistic software version 23.0 (IBM, Corp., New York).

\section{Results}

\section{Patient characteristics}

Between 2011 and 2015 in 94 patients, ASV therapy was initiated. Exclusion criteria included death before follow-up visit in 2015, inaccessible data on late therapy usage at the reappointment date 2015 and initiation of ASV therapy less than 2 months before the reappointment date (Fig. 1). From the remaining 69 patients, 61 appeared to the follow-up visit and 8 chose to terminate ASV therapy before the end of 2015 due to discomfort and lack of symptomatic benefit (Fig. 1). 
The analysis population consisted predominantly of elderly mildly obese men. The majority fulfilled the diagnostic criteria of heart failure either with reduced or with preserved left ventricular ejection fraction (Table 1). The vast majority of patients had echocardiographic abnormalities such as left atrial enlargement, left ventricular hypertrophy, and/or diastolic dysfunction (Table 1).

The analysis population had severe predominantly CSA with a mildly reduced mean $\mathrm{SaO}$ 2. Sleep was fragmented as well as sleep efficiency (SE); N3 and REM sleep were reduced. Sleep onset latency was prolonged (Table 2). Patients reported a moderate degree of subjective daytime sleepiness (Table 2).

\section{Adaptive servo-ventilation usage}

The mean early ASV usage was $4.8 \pm 2.5 \mathrm{~h}$, and the mean late usage was $4.1 \pm 3.0 \mathrm{~h}$ in the total population (Fig. 2a). Eleven patients (15.9\%) stopped ASV therapy within the follow-up period (median 17 months). Patients were stratified into a group with late ASV usage $\geq 4 \mathrm{~h}$ (high late ASV usage; $n=$ $39,57 \%$ ) and a group with late ASV usage $<4 \mathrm{~h}$ (low late ASV usage: $n=30,44 \%$, Table 1. Patients with high late ASV usage had similar early and late usage $(6.1 \pm 1.7$ vs. $6.4 \pm 1.4$, $p=0.399$; Fig. 2 b), while patients with low late ASV usage had a further fall from early to late ASV usage (3.2 \pm 2.6 vs. $1.2 \pm 1.4 \mathrm{~h}, p<0.001$; Fig. $2 \mathrm{c}$ ). Among patients with documented high early ASV usage ( $\geq 4 \mathrm{~h}$ ), the proportion of high

Table 1 Patient characteristics at baseline

\begin{tabular}{ll}
\hline & Analysis population \\
\hline$n(\%)$ & $\mathbf{6 9}(\mathbf{1 0 0} \%)$ \\
Age [years] & $69 \pm 10$ \\
Body mass index $\left[\mathrm{kg} / \mathrm{m}^{2}\right]$ & $31 \pm 6$ \\
Male sex [n (\%)] & $66(96 \%)$ \\
Diagnosis of heart failure & \\
No heart failure $[n(\%)]$ & $14(20 \%)$ \\
HFrEF $[n(\%])$ & $17(25 \%)$ \\
HFpEF $[n(\%)]$ & $38(55 \%)$ \\
NYHA-classification (in HFrEF and HFpEF patients) \\
NYHA I, II $[n(\%)]$ & $34(62 \%)$ \\
NYHA III, IV $[n(\%)]$ & $21(38 \%)$ \\
Ejection fraction $[\%]$ & $49 \pm 14$ \\
Left atrial enlargement $[n(\%)]$ & $39(57 \%)$ \\
Left ventricular hypertrophy $[n(\%)]$ & $43(62 \%)$ \\
Diastolic dysfunction $[n(\%)]$ & $19(28 \%)$
\end{tabular}

Data are presented as mean \pm standard deviation or $n(\%)$. NYHA New York Heart Association functional class, $H F r E F$ heart failure with reduced ejection fraction, $H F p E F$ heart failure with preserved ejection fraction
Table 2 Diagnostic polysomnography

Analysis population

\begin{tabular}{ll}
\hline$n(\%)$ & $\mathbf{6 9}(\mathbf{1 0 0 \%})$ \\
Sleep onset latency, $\min$ & $25.0[14.3 ; 41.1]^{*}$ \\
Sleep efficiency, \% & $73 \pm 16$ \\
Apnea-hypopnea index, $n / h$ & $48 \pm 20$ \\
Apnea index, $n / h$ & $34 \pm 22$ \\
Central apnea index, $n / h$ & $20 \pm 17$ \\
$\mathrm{Min}_{\mathrm{SaO}}, \%$ & $77 \pm 10$ \\
$\mathrm{Mean} \mathrm{SaO}_{2}, \%$ & $92 \pm 2$ \\
Oxygen desaturation index, $n / h$ & $44 \pm 18$ \\
Respiratory arousal index, $n / h$ & $38 \pm 16$ \\
Sleep stage N1, \% & $31 \pm 17$ \\
Sleep stage N2, \% & $45 \pm 14$ \\
Low wave sleep (N3), \% & $12 \pm 9$ \\
Rapid-eye-movement sleep, \% & $12 \pm 6$ \\
ESS baseline & $9 \pm 5$ \\
\hline
\end{tabular}

Data are presented as mean \pm standard deviation or $n(\%)$. * Data are presented as median [interquartile range]

late ASV usage was significantly greater compared with low late ASV usage ( 72 vs. $28 \%$ ).

\section{Patient characteristics according to late adaptive servo-ventilation usage}

Thirty-nine patients used their device $\geq 4 \mathrm{~h}(57 \%$, high late ASV usage), and 30 patients used their device $<4 \mathrm{~h}(44 \%$, low late ASV usage). Groups did not differ with respect to demographic parameters (eTable 1). In the low late ASV usage group, the proportion of patients with $\mathrm{AF}$ and ischemic cardiomyopathy was significantly higher compared with the high late ASV usage group (eTable 1).

\section{Sleep parameters and applied pressures}

Comparison of the usage groups with respect to the PSGs of diagnostic and ASV initiation night showed no significant differences (Fig. 3). In the group "usage $<4 \mathrm{~h}$," sleep efficiency showed a reduction in the ASV night (Fig. 3). Groups had similar pressure settings 1 month after therapy initiation (mean EPAP: usage $<4$ h: $8.2 \pm 2.6$, usage $\geq 4$ h: $7.6 \pm 2.1 p=0.890$; mean maximum inspiratory pressure support usage $<4 \mathrm{~h}: 6.5$ \pm 4.3 , usage $\geq 4$ h: $7.1 \pm 4.5 p=0.624$ ).

\section{Subjective benefit}

Patients who stated a subjective benefit from ASV therapy used their device significantly more ( $p$ value $=0.038$ ) (Fig. 3 ) with a total of $82 \%$ of the patients reporting subjective 



Fig. 2 a Box plot shows in the total population a significant fall from early to late ASV usage $(4.8 \pm 2.5 \mathrm{~h}$ versus $4.1 \pm 3.0 \mathrm{~h}, p<0.001)$. The total range of early and late ASV usage was 0 to $11 \mathrm{~h}$ and 0 to $10 \mathrm{~h}$ per night, respectively. b Patients of the high late ASV usage group had similar early and late usage $(6.1 \pm 1.7$ vs. $6.4 \pm 1.4, p=0.399)$. c Patients of the low late ASV usage group had a further fall from early to late ASV usage $(3.2 \pm 2.6$ vs. $1.2 \pm 1.4 \mathrm{~h}, p<0.001)$. Box plot shows median usage (horizontal line) with IQR. Whiskers show maximum/ minimum value still within $1.5 \mathrm{IQR}$ of upper/lower quartile. Outliners are depicted as dots. Mean usage is depicted as cross. Early usage: ASV usage in the first month after therapy initiation, late usage: ASV usage in the last month before follow-up visit in 2015



Fig. 3 Comparison of the usage groups. Panel a compares the subjective benefit in the ASV usage groups. Subjective benefit was assessed at the reappointment date with dichotomous nominal scale: "yes" if patients perceived ASV therapy beneficial, "no" if patients perceived no benefit from ASV therapy. Patients with usage $\geq 4 \mathrm{~h}$ reported significantly more often subjective benefit. Panel $b$ and $c$ compare the ASV usage groups at

\section{$=0.038$}

- subjective benefit "no"



diagnostic and ASV initiation night. Panel $b$ shows the tendency of prolongation of slow wave sleep in patients with ASV usage $\geq 4 \mathrm{~h}$. Panel $c$ shows the significant prolongation of REM sleep in usage group "usage $\geq 4 \mathrm{~h}$ ". $N 3$ slow wave sleep, REM rapid-eye-movement sleep 
benefit from the therapy. In mean patients showed no excessive signs of daytime sleepiness prior to therapy with the mean ESS baseline being $9 \pm 5$ points (Table 2). Daytime sleepiness showed no influence on ASV usage behavior (eTable 1).

\section{Regression models}

A univariable regression model was used for variables showing an association with late ASV usage: early usage $(p \leq 0.001)$, the absence of $\operatorname{AF}(p=0.021)$, the absence of ischemic cardiomyopathy ( $p=0.043$ ), and subjective benefit $(p \leq 0.001)$ proofed to be significant predictors for late usage. An improvement of sleep quality was associated with late usage (Delta REM: $p=$ 0.036; Table 3). Left ventricular ejection fraction was not associated with late ASV usage (Beta coefficient [95\% confidence interval]: -0.07 [ $-5.134,3.49], p=0.701$ ).

In multivariable analysis, short duration of slow wave sleep at baseline and subjective benefit predicted longer late ASV usage, when the model was adjusted for all potential predictors with $p<0.1$ in the univariable analysis (Table 3 ), as well as age, BMI, and sex (Table 4). Early usage could not be included into that model because of multi-correlation with the subjective benefit. None of the potential predictors for ASV usage such as age, sex, BMI, subjective benefit, atrial fibrillation, ischemic cardiomyopathy, N3 in diagnostic PSG, change of rapid-eye-movement sleep, and subjective benefit from ASV was significantly associated with early ASV usage $\geq 4 \mathrm{~h}$ (multivariable binary regression analysis, $p>0.05$ for each potential predictor). Only N3 in diagnostic PSG was significantly associated with late ASV usage $\geq 4 \mathrm{~h}$ (multivariable binary regression analysis, Beta [95\% CI]: 0.891 [0.798; 0.995]; $p=0.04$ ).

In order to assess the correlation between $\mathrm{AHI}$ at baseline/ arousal index at baseline and slow wave sleep/non-REM sleep, respectively, simple linear regression models were performed. High AHI and high arousal index at baseline correlated significantly with low percentage of slow wave sleep at baseline $\left(R^{2} 0.119, p=0.016\right.$ and $\left.R^{2} 0.262, p<0.001\right)$,
Table 3 Predictors for long-term usage of adaptive servo-ventilation-univariable regression model*

\begin{tabular}{lll}
\hline Variable & Beta $(95 \% \mathrm{CI})[\mathrm{min}]$ & $p$ value \\
\hline Age (baseline) [years] & $-2.5(-6.9 ; 1.9)$ & 0.264 \\
Body mass index [kg/m ${ }^{2}$ ] & $-2.193(-10.077 ; 5.690)$ & 0.580 \\
Sex [male vs female] & $145.591(-63.549 ; 354.731)$ & 0.169 \\
Atrial fibrillation [yes vs no] & $-98.295(-181.515 ;-15.076)$ & $\mathbf{0 . 0 2 1}$ \\
Ischemic cardiomyopathy [yes vs no] & $-87.351(-171.978 ;-2.725)$ & $\mathbf{0 . 0 4 3}$ \\
NYHA [I, II vs III, IV] & $14.314(-75.619 ; 104.246)$ & 0.752 \\
HFrEF vs. not & $16.791(-69.218 ; 102.799)$ & 0.697 \\
Type of CSA [CSA in HF vs primary CSA vs & $60.228(-16.972 ; 137.427)$ & 0.123 \\
treatment emergent CSA] & & \\
Epworth sleepiness scale score & $-0.550(-11.001 ; 9.901)$ & 0.916 \\
Sleep efficiency & $-1.958(-5.079 ; 1.163)$ & 0.213 \\
Apnea-hypopnea index & $0.041(-2.349 ; 2.431)$ & 0.973 \\
Central apnea index & $-0.025(-2.914 ; 2.864)$ & 0.986 \\
Slow wave sleep (N3) [\%] & $-4.466(-9.426 ; 0.493)$ & 0.076 \\
Rapid-eye-movement sleep [\%] & $-3.432(-11.454 ; 4.591)$ & 0.394 \\
Delta Epworth sleepiness scale score & $-0.169(-15.332 ; 14993)$ & 0.982 \\
Delta sleep efficiency & $1.580(-0.997 ; 4.158)$ & 0.223 \\
Delta apnea-hypopnea index & $0.151(-2.518 ; 2.820)$ & 0.910 \\
Delta central apnea index & $0.622(-2.271 ; 3.515)$ & 0.667 \\
Delta slow wave sleep & $2.187(-2.262 ; 6.636)$ & 0.328 \\
Delta rapid-eye-movement sleep & $5.504(0.377 ; 10.632)$ & $\mathbf{0 . 0 3 6}$ \\
Subjective benefit [yes vs no] & $191.300(82.182-300.418)$ & $\mathbf{0 . 0 0 1}$ \\
Mean EPAP [cmH $\left.{ }_{2} \mathrm{O}\right]$ & $-0.992(-21.782-19.798)$ & 0.924 \\
Mean IPAP [cmH $\left.{ }_{2} \mathrm{O}\right]$ & $2.379(-16.150-20.908)$ & 0.797 \\
\hline & & \\
\hline
\end{tabular}

Values with $p \leq 0.01$ are printed in bold. Beta beta-coefficient, $C I$ confidence interval, NYHA New York Heart Association functional class, $H F r E F$ heart failure with reduced ejection fraction, $H F p E F$ heart failure with preserved ejection fraction, $C S A$ central sleep apnea, $E P A P$ expiratory positive airway pressure, $P S$ pressure support, IPAP inspiratory positive airway pressure. All Delta values are value from ASV initiation night minus value from diagnostic night - except Delta ESS: value from follow-up visit minus value from diagnostic night. *Long-term usage $=$ mean nocturnal use of adaptive servo-ventilation in minutes 
Table 4 Predictors for long-term usage to adaptive servo ventilation - multivariable regression model*

\begin{tabular}{llc}
\hline Variables & Beta $(95 \% \mathrm{CI})$ & $p$ value \\
\hline Age [years] & $-2.405(-7.459 ; 2.650)$ & 0.339 \\
Body Mass Index $\left[\mathrm{kg} / \mathrm{m}^{2}\right]$ & $-1.639(-10.903 ; 7.625)$ & 0.720 \\
Male sex & $64.335(-138.140 ; 266.811)$ & 0.521 \\
Atrial fibrillation [yes vs no] & $-82.479(-178.341 ; 13.384)$ & 0.089 \\
Ischemic cardiomyopathy [yes vs no] & $-73.782(-163.371 ; 15.807)$ & 0.103 \\
N3 in diagnostic PSG [\%] & $-5.874(-10.587 ;-1.161)$ & $\mathbf{0 . 0 1 6}$ \\
Delta rapid-eye-movement sleep & $1.703(-3.377 ; 6.783)$ & 0.499 \\
Subjective benefit from ASV [yes vs no] & $147.800(39.988 ; 255.612)$ & $\mathbf{0 . 0 0 9}$ \\
Model summary & $\mathrm{R}^{2} 0.546 ; \mathrm{F}=4.50$ & \\
\hline
\end{tabular}

Values with $p \leq 0.05$ are printed in bold. Beta beta-coefficient, $C I$ confidence interval, $N 3$ slow wave sleep. Delta is value from ASV initiation night minus value from diagnostic night. *Long-term usage = mean nocturnal use of adaptive servo-ventilation in minutes whereas there was no significant correlation between AHI and arousal index at baseline and percentage of REM sleep at baseline $\left(R^{2} 0.013, p=0.436\right.$ and $\left.R^{2} 0.020, p=336\right)$. High central apnea index was neither significantly associated with low percentage of slow wave sleep nor with REM sleep at baseline $\left(R^{2} 0.003\right.$ and $R^{2} 0.028 ; p>0.05$ for both linear regression models).

\section{Discussion}

This analysis confirmed that high early usage of ASV predicts late ASV usage. In addition, this analysis detected possible predictors of late ASV usage in a sample of patients with chronic heart failure: short duration of slow wave sleep at diagnostic PSG and the subjective benefit from ASV therapy.

In accordance with previous CPAP [34-36] and ASV [37] studies, high early usage was a strong predictor of high late usage $(p<0.01)$. The consistency of this finding in various analyses underlines how early on (early usage was defined from 3 days to 1 month in different analyses) a usage pattern is adopted and underlines the importance of a diligent adaption to the novel therapy as outlined in guidelines for the management of SDB [6]. Attention to comfort with the face mask and the applied positive airway pressure as well as proper communication between the patient and the health worker from the beginning of the therapy on could be a key in preventing patients from dropping out of therapy. Also new strategies as the telemedicine-based proactive patient management, which initiates patient contact, information sharing, and education through a cloud-based remote monitoring system, could be of use to improve therapy usage $[38,39]$. In this analysis as well as in the ASV study of Perger et al. [37] in patients with heart failure and sleep apnea and a recent study by van Ryswyk et al. [36] in patients with obstructive sleep apnea and cardiovascular disease with CPAP therapy, adherence at 1 month was the strongest predictor of long time adherence.

Two to 6 weeks after PAP initiation could be a crucial time period during which usage should be evaluated, and patients should be monitored more closely to identify patients with a higher risk of therapy drop out and/or low therapy usage [6, $36,37]$. The fall of daily usage in the present analysis ( 4.8 to $4.1 \mathrm{~h}$ ) was similar to the findings from the ASV group of the SERVE-HF trial in patients with HFrEF and CSA with a mean usage of $4.1 \mathrm{~h}$ at 2 weeks and $3.4 \mathrm{~h}$ at 24 months [24].

The second very strong predictor of late usage was subjective benefit. The concordance of subjective benefit and therapy usage is easily understood. It is plausible that patients who experience a therapy as beneficial are more likely to continue with it. To assess a subjective benefit could therefore be helpful in predicting ASV usage. In this analysis, $82 \%$ of the collective felt a beneficial effect of ASV therapy. This could be interpreted as a good sign for ASV therapy in patients in HF (keeping in mind that the subgroup of HF patients in whom ASV is contradicted is fairly small [4]) although a possible placebo effect cannot be ruled out.

Seventy-nine percent of the patients with CSA who are treated with ASV suffer from impaired cardiac function [4]. Patients with heart failure and either OSA [40] or CSA $[9,41]$ are usually not sleepy [42]. Compared with the general population with a similar degree of OSA heart failure, patients have a longer sleep onset latency, shorter total sleep time, and a lower ESS [40]. One mechanism might be that heart failure patients with sleep-disordered breathing show increased sympathetic nerve activity in comparison with those without [43]. It is a consistent finding in heart failure populations that sleep quality and changes in sleep quality do not strongly correlate with daytime sleepiness $[12,44,45]$. The finding that daytime sleepiness shows no influence on ASV-usage is in accordance with a small study from Philippe et al. [9]. 
The influence of a subjective benefit on therapy usage is underlined by the finding of low slow wave sleep at diagnostic polysomnography predicting high late usage. In central sleep apnea, low N3 percentage is a sign that CSA is disrupting sleep [13]. This is underlined by the significant correlation of high AHI and high arousal index with low slow wave sleep at baseline in this sample $\left(R^{2}\right.$ $0.119, p=0.016$ and $\left.R^{2} 0.262, p<0.001\right)$. Central sleep apnea mainly occurs in non-REM sleep [46] (underlined by the fact that there was no significant correlation between AHI/arousal index with percentage of REM sleep $\left(R^{2} 0.013, p=0.436\right.$ and $\left.R^{2} 0.020, p=336\right)$. With slow wave sleep being the most important non-REM sleep phase for nocturnal recreation [13, 47], low slow wave sleep at baseline being a predictor for late usage might be interpreted as a sign that patients who find greater relief with their therapy are more likely to continue with it [35]. This interpretation goes hand in hand with earlier findings in CPAP compliance studies in which sleep efficiency at titration night [48] and lower percentage of N2 sleep with higher percentage of REM sleep at initiation night [35] was found in good therapy users. In this analysis, tendencies in the usage group $\geq 4 \mathrm{~h}$ showed more impaired sleep structure at baseline, which improved on ASV. In contrast, in the usage group $<4 \mathrm{~h}$, a worsening of sleep efficiency from diagnostic to initiation night was observed. In accordance with these results, Lewis et al. showed that patients who reported problems at their first night of CPAP later used their therapy less [49]. Collen et al. and Lettieri et al. report on an association between use of sedative hypnotics in the titration night and longer TST and higher sleep efficiency, which was also a significant predictor of higher short term CPAP adherence [50, 51].

\section{Clinical perspective}

Variables predicting usage behavior could be helpful in guiding the selection of patients for ASV treatment and for extended proactive patient management in order to optimize device usage [39], bearing in mind that longer usage of PAP treatment leads to greater therapy success [13-15]. The present data underscore that early usage of ASV predicts long-term usage. Thus, early feedback and patient support, possibly with the use of telemedicine based proactive patient management $[38,39]$, are warranted. Patients with impaired sleep structure (shorter slow wave sleep), with the potential to improve sleep, and those with subjective benefit from ASV therapy have higher long-term usage of ASV: In those with normal sleep structure before therapy and those patients without subjective benefit from ASV treatment, indication should be thoroughly reevaluated.

\section{Limitations}

This retrospective analysis is subject to some limitations. Not all possible predictors of ASV usage were investigated-especially psychological factors [52] have not been analyzed. Also, some physiological parameters such as lung function and blood gas measures were not systematically assessed. Some known predictors for positive airway pressure intolerance such as high nasal resistance $[17,18]$, uncomfortable mask [19-21], financial aspects, loss of intimacy with the bed partner [22], and claustrophobia $[22,23]$ were not systematically assessed. As this is an observational study, causal effects cannot be proven, and selection bias can occur. Because of the patients forming part of everyday clinical practice, equal conditions could not be provided: different devices (ResMed or Respironics from Phillips), different types of masks [53] might have influenced usage behavior. On the other hand, the present study presents a real-life clinical setting. A further limitation is that the timespan between diagnostic PSG, ASV initiation, and reappointment date differed in the studied population. But, since the median time from ASV initiation to the reappointment date was 17 months, we considered it long enough to be able to compare late usage. In addition, it is possible that our sample of 69 patients is too small to detect all modulators of late ASV usage. The night-to-night variability of severity of SDB and sleep quality may have diluted the findings in the present analysis, since in clinical routine, rarely repeated polysomnographies are performed.

\section{Conclusion}

Early ASV usage is a strong predictor of late ASV usage. In addition, low slow wave sleep during diagnostic polysomnography and subjective benefit may contribute to high late ASV usage. Findings should be confirmed in analyses of major ongoing prospective registries of ASV such as READ-ASV (Phase I and II, NCT03032029, NCT04331821) or autoSVREGDE (NCT03421704).

Authors' contributions L. Kolb, M. Arzt, and M. Malfertheiner were involved in the conception, hypotheses delineation, design of the study, acquisition of the data, the analysis and interpretation of such information, writing the article, and in its revision prior to submission. K. Heider was substantially involved in data collection and interpretation and in the revision of the article prior to submission. S. Stadler and L. S. Maier were substantially involved in the interpretation of the data and in the revision of the article prior to submission.

Funding Open Access funding provided by Projekt DEAL.

Data availability Data are available upon request. 


\section{Compliance with ethical standards}

Conflicts of interest M. Arzt reports grants and personal fees from Philips Respironics and ResMed; grants from the ResMed Foundation; and personal fees from Novartis, BresoTec, Boehringer-Ingelheim, Inspire, JAZZ Pharmaceuticals, and NRI outside the submitted work. All other authors report no conflict of interest.

Ethics approval This retrospective analysis was approved by the Ethics Committee of the University of Regensburg (approval no. 15-101-0255) and was conducted in accordance with the principles of Good Clinical Practice and the Declaration of Helsinki.

Informed consent The requirement for informed consent was waived because of the retrospective study design.

Open Access This article is licensed under a Creative Commons Attribution 4.0 International License, which permits use, sharing, adaptation, distribution and reproduction in any medium or format, as long as you give appropriate credit to the original author(s) and the source, provide a link to the Creative Commons licence, and indicate if changes were made. The images or other third party material in this article are included in the article's Creative Commons licence, unless indicated otherwise in a credit line to the material. If material is not included in the article's Creative Commons licence and your intended use is not permitted by statutory regulation or exceeds the permitted use, you will need to obtain permission directly from the copyright holder. To view a copy of this licence, visit http://creativecommons.org/licenses/by/4.0/.

\section{References}

1. Teschler H, Dohring J, Wang YM et al (2001) Adaptive pressure support servo-ventilation: a novel treatment for Cheyne-Stokes respiration in heart failure. Am J Respir Crit Care Med 164(4):614619. https://doi.org/10.1164/ajrccm.164.4.9908114

2. Arzt M, Wensel R, Montalvan S, Schichtl T, Schroll S, Budweiser S, Blumberg FC, Riegger GAJ, Pfeifer M (2008) Effects of dynamic bilevel positive airway pressure support on central sleep apnea in men with heart failure. Chest 134(1):61-66. https://doi.org/10. 1378/chest.07-1620

3. Schindhelm F, Fox H, Oldenburg O, Horstkotte D (2018) Bitter T Cheyne-Stokes-Atmung.: (Notwendiger) Wissensstand aktuell. Somnologie (Berl) 22:45-75

4. Malfertheiner MV, Lerzer C, Kolb L, Heider K, Zeman F, Gfüllner F, Maier LS, Pfeifer M, Arzt M (2017) Whom are we treating with adaptive servo-ventilation? A clinical post hoc analysis. Clin Res Cardiol 106(9):702-710. https://doi.org/10.1007/s00392-0171112-3

5. Randerath W, Verbraecken J, Andreas S, Arzt M, Bloch KE, Brack T, Buyse B, de Backer W, Eckert DJ, Grote L, Hagmeyer L, Hedner J, Jennum P, la Rovere MT, Miltz C, McNicholas WT, Montserrat J, Naughton M, Pepin JL, Pevernagie D, Sanner B, Testelmans D, Tonia T, Vrijsen B, Wijkstra P, Levy P (2017) Definition, discrimination, diagnosis and treatment of central breathing disturbances during sleep. Eur Respir J 49(1):1600959. https://doi.org/10.1183/ 13993003.00959-2016

6. Mayer G, Arzt M, Braumann B, Ficker JH, Fietze I, Frohnhofen H, Galetke W, Maurer JT, Orth M, Penzel T, Pistner H, Randerath W, Rösslein M, Sitter H, Stuck BA (2017) German S3 guideline nonrestorative sleep/sleep disorders, chapter "Sleep-related breathing disorders in adults," short version: German Sleep Society (Deutsche Gesellschaft fur Schlafforschung und Schlafmedizin,
DGSM). Somnologie (Berl) 21(4):290-301. https://doi.org/10. 1007/s11818-017-0136-2

7. Oldenburg O, Arzt M, Bitter T, Bonnemeier H, Edelmann F, Fietze I, Podszus T, Schäfer T, Schöbel C, Skobel E, Skowasch D, Penzel T, Nienaber C (2015) Positionspapier "Schlafmedizin in der Kardiologie". Kardiologe 9(2):140-158. https://doi.org/10.1007/ s12181-015-0654-8

8. Cowie MR, Woehrle H, Wegscheider K, Angermann C, d'Ortho MP, Erdmann E, Levy P, Simonds AK, Somers VK, Zannad F, Teschler H (2015) Adaptive servo-ventilation for central sleep apnea in systolic heart failure. N Engl J Med 373(12):1095-1105. https://doi.org/10.1056/NEJMoa1506459

9. Philippe C, Stoica-Herman M, Drouot X et al (2006) Compliance with and effectiveness of adaptive servoventilation versus continuous positive airway pressure in the treatment of Cheyne-Stokes respiration in heart failure over a six month period. Heart 92(3): 337-342. https://doi.org/10.1136/hrt.2005.060038

10. Kasai T, Usui Y, Yoshioka T, Yanagisawa N, Takata Y, Narui K, Yamaguchi T, Yamashina A, Momomura SI, JASV Investigators (2010) Effect of flow-triggered adaptive servo-ventilation compared with continuous positive airway pressure in patients with chronic heart failure with coexisting obstructive sleep apnea and Cheyne-Stokes respiration. Circ Heart Fail 3(1):140-148. https:// doi.org/10.1161/CIRCHEARTFAILURE.109.868786

11. Hastings PC, Vazir A, Meadows GE, Dayer M, Poole-Wilson PA, McIntyre HF, Morrell MJ, Cowie MR, Simonds AK (2010) Adaptive servo-ventilation in heart failure patients with sleep apnea: a real world study. Int J Cardiol 139(1):17-24. https://doi.org/ 10.1016/j.ijcard.2008.08.022

12. Hetzenecker A, Escourrou P, Kuna ST, Series F, Lewis K, Birner C, Pfeifer M, Arzt M (2016) Treatment of sleep apnea in chronic heart failure patients with auto-servo ventilation improves sleep fragmentation: a randomized controlled trial. Sleep Med 17:25-31. https:// doi.org/10.1016/j.sleep.2015.08.020

13. Hetzenecker A, Roth T, Birner C, Maier LS, Pfeifer M, Arzt M (2016) Adaptive servo-ventilation therapy of central sleep apnoea and its effect on sleep quality. Clin Res Cardiol 105(3):189-195. https://doi.org/10.1007/s00392-015-0904-6

14. Weaver TE, Maislin G, Dinges DF, Bloxham T, George CFP, Greenberg H, Kader G, Mahowald M, Younger J, Pack AI (2007) Relationship between hours of CPAP use and achieving normal levels of sleepiness and daily functioning. Sleep 30(6):711-719

15. Antic NA, Catcheside P, Buchan C, Hensley M, Naughton MT, Rowland S, Williamson B, Windler S, McEvoy RD (2011) The effect of CPAP in normalizing daytime sleepiness, quality of life, and neurocognitive function in patients with moderate to severe OSA. Sleep 34(1):111-119

16. Montesi SB, Edwards BA, Malhotra A, Bakker JP (2012) The effect of continuous positive airway pressure treatment on blood pressure: a systematic review and meta-analysis of randomized controlled trials. J Clin Sleep Med 8(5):587-596. https://doi.org/ $10.5664 / \mathrm{jcsm} .2170$

17. Lozano L, Tovar JL, Sampol G, Romero O, Jurado MJ, Segarra A, Espinel E, Ríos J, Untoria MD, Lloberes P (2010) Continuous positive airway pressure treatment in sleep apnea patients with resistant hypertension: a randomized, controlled trial. J Hypertens 28(10):2161-2168. https://doi.org/10.1097/HJH. 0b013e32833b9c63

18. Wimms A, Ketheeswaran S, Ziegenbein C, Jennings L, Woehrle H (2016) Impact of a new nasal pillows mask on patients' acceptance, compliance, and willingness to remain on CPAP therapy. Sleep Disord 2016:6713236-6713236. https://doi.org/10.1155/2016/ 6713236

19. Oldenburg O, Bitter T, Lehmann R, Korte S, Dimitriadis Z, Faber L, Schmidt A, Westerheide N, Horstkotte D (2011) Adaptive servoventilation improves cardiac function and respiratory stability. 
Clin Res Cardiol 100(2):107-115. https://doi.org/10.1007/s00392010-0216-9

20. Bitter T, Westerheide N, Faber L, Hering D, Prinz C, Langer C, Horstkotte D, Oldenburg O (2010) Adaptive servoventilation in diastolic heart failure and Cheyne-Stokes respiration. Eur Respir J 36(2):385-392. https://doi.org/10.1183/09031936.00045609

21. Barbé F, Durán-Cantolla J, Sánchez-de-la-Torre M, MartínezAlonso M, Carmona C, Barceló A, Chiner E, Masa JF, Gonzalez M, Marín JM, Garcia-Rio F, Diaz de Atauri J, Terán J, Mayos M, de la Peña M, Monasterio C, del Campo F, Montserrat JM, Spanish Sleep and Breathing Network (2012) Effect of continuous positive airway pressure on the incidence of hypertension and cardiovascular events in nonsleepy patients with obstructive sleep apnea: a randomized controlled trial. JAMA 307(20):2161-2168. https:// doi.org/10.1001/jama.2012.4366

22. Kribbs NB, Pack AI, Kline LR, Smith PL, Schwartz AR, Schubert NM, Redline S, Henry JN, Getsy JE, Dinges DF (1993) Objective measurement of patterns of nasal CPAP use by patients with obstructive sleep apnea. Am Rev Respir Dis 147(4):887-895. https:// doi.org/10.1164/ajrccm/147.4.887

23. Biener L, Pizarro C, Nickenig G, Skowasch D (2019) Obstructive sleep apnea and cardiovascular disease: a cause apparent but not yet evident. Somnologie 23(4):320-321. https://doi.org/10.1007/ s11818-019-0212-x

24. Cowie MR, Woehrle H, Wegscheider K, Angermann C, d'Ortho MP, Erdmann E (2015) Supplementary appendix for adaptive servoventilation for central sleep apnea in systolic heart failure. $\mathrm{N}$ Engl $\mathrm{J}$ Med 373(12):1095-1105. https://doi.org/10.1056/ NEJMoa1506459

25. Arzt M, Schroll S, Series F, Lewis K, Benjamin A, Escourrou P, Luigart R, Kehl V, Pfeifer M (2013) Auto-servoventilation in heart failure with sleep apnoea: a randomised controlled trial. Eur Respir J 42(5):1244-1254. https://doi.org/10.1183/09031936.00083312

26. Schadlich S, Konigs I, Kalbitz F et al (2004) Cardiac efficiency in patients with Cheyne-Stokes respiration as a result of heart insufficiency during long-term nasal respiratory treatment with adaptive servo ventilation (AutoSet CS) (Kardiale Leistungsfahigkeit bei Patienten mit Cheyne-Stokes-Atmung infolge Herzinsuffizienz wahrend langfristiger nasaler Beatmungstherapie mittels adaptiver Servoventilation (AutoSet CS)). Z Kardiol 93(6):454-462. https:// doi.org/10.1007/s00392-004-0083-3

27. Johns MW (1991) A new method for measuring daytime sleepiness: the Epworth sleepiness scale. Sleep 14(6):540-545

28. Heider K, Arzt M, Lerzer C, Kolb L, Pfeifer M, Maier LS, Gfüllner F, Malfertheiner MV (2018) Adaptive servo-ventilation and sleep quality in treatment emergent central sleep apnea and central sleep apnea in patients with heart disease and preserved ejection fraction. Clin Res Cardiol 107(5):421-429. https://doi.org/10.1007/s00392018-1203-9

29. Iber C (2007) The AASM manual for the scoring of sleep and associated events: rules, terminology and technical specifications.: Academy of Sleep Medicine, Westchester. American Academy of Sleep Medicine

30. Berry RB, Budhiraja R, Gottlieb DJ, Gozal D, Iber C, Kapur VK, Marcus CL, Mehra R, Parthasarathy S, Quan SF, Redline S, Strohl KP, Davidson Ward SL, Tangredi MM, American Academy of Sleep Medicine (2012) Rules for scoring respiratory events in sleep: update of the 2007 AASM Manual for the Scoring of Sleep and Associated Events. Deliberations of the Sleep Apnea Definitions Task Force of the American Academy of Sleep Medicine. J Clin Sleep Med 8(5):597-619. https://doi.org/10.5664/jcsm.2172

31. Penzel T, Schobel C, Fietze I (2015) Revise respiratory event criteria or revise severity thresholds for sleep apnea definition? J Clin Sleep Med 11(12):1357-1359. https://doi.org/10.5664/jcsm. 5262
32. Berry RB, Brooks R, Gamaldo CE et al. (2014) The AASM manual for the scoring of sleep and associated events: rules, terminology, and technical specification, Version 2.1. www.aasmnet.org. Darien, IL. American Academy of Sleep Medicine

33. Mayer G, Rodenbeck A, Hajak G (1995) Störungen des circadianen Schlaf-Wach-Rhythmus-diagnostische und therapeutische Prinzipien (Disorders of the circadian sleep-wake rhythmdiagnostic and therapeutic principles). Wien Med Wochenschr 145(17-18):423-430

34. Budhiraja R, Parthasarathy S, Drake CL, Roth T, Sharief I, Budhiraja P, Saunders V, Hudgel DW (2007) Early CPAP use identifies subsequent adherence to CPAP therapy. Sleep 30(3): 320-324

35. Somiah M, Taxin Z, Keating J, Mooney AM, Norman RG, Rapoport DM, Ayappa I (2012) Sleep quality, short-term and long-term CPAP adherence. J Clin Sleep Med 8(5):489-500. https://doi.org/10.5664/jcsm.2138

36. van Ryswyk E, Anderson CS, Antic NA et al (2019) Predictors of long-term adherence to continuous positive airway pressure in patients with obstructive sleep apnea and cardiovascular disease. Sleep 42(10):zsz152. https://doi.org/10.1093/sleep/zsz152

37. Perger E, Lyons OD, Inami T, Smith S, Floras JS, Logan AG, Bradley TD, ADVENT-HF Investigators, ADVENT-HF Trial Executive Committee, ADVENT-HF Steering Committee, ADVENT-HF Data and Safety Monitoring Committee, ADVENT-HF Event Adjudication Committee, ADVENT-HF Investigators (2018) Predictors of one year compliance with adaptive servo-ventilation in patients with heart failure and sleepdisordered breathing: preliminary data from the ADVENT-HF Trial. European Respiratory Journal 2:1801626. https://doi.org/10. 1183/13993003.01626-2018

38. Woehrle H, Ficker JH, Graml A, Fietze I, Young P, Teschler H, Arzt M (2017) Telemedicine-based proactive patient management during positive airway pressure therapy: impact on therapy termination rate. Somnologie (Berl) 21(2):121-127. https://doi.org/10. 1007/s11818-016-0098-9

39. Hwang D, Chang JW, Benjafield AV, Crocker ME, Kelly C, Becker KA, Kim JB, Woodrum RR, Liang J, Derose SF (2018) Effect of telemedicine education and telemonitoring on continuous positive airway pressure adherence. The Tele-OSA Randomized Trial. Am J Respir Crit Care Med 197(1):117-126. https://doi. org/10.1164/rccm.201703-0582OC

40. Arzt M, Young T, Finn L et al (2006) Sleepiness and sleep in patients with both systolic heart failure and obstructive sleep apnea. Arch Intern Med 166(16):1716-1722. https://doi.org/10.1001/ archinte.166.16.1716

41. Arzt M, Harth M, Luchner A, Muders F, Holmer SR, Blumberg FC, Riegger G̈AJ, Pfeifer M (2003) Enhanced ventilatory response to exercise in patients with chronic heart failure and central sleep apnea. Circulation 107(15):1998-2003. https://doi.org/10.1161/ 01.CIR.0000065227.04025.C2

42. Hastings PC, Vazir A, O'Driscoll DM et al (2006) Symptom burden of sleep-disordered breathing in mild-to-moderate congestive heart failure patients. Eur Respir J 27(4):748-755. https://doi.org/10. 1183/09031936.06.00063005

43. Spaak J, Egri ZJ, Kubo T, Yu E, Ando SI, Kaneko Y, Usui K, Bradley TD, Floras JS (2005) Muscle sympathetic nerve activity during wakefulness in heart failure patients with and without sleep apnea. Hypertension 46(6):1327-1332. https://doi.org/10.1161/01. HYP.0000193497.45200.66

44. Atalla A, Carlisle TW, Simonds AK, Cowie MR, Morrell MJ (2017) Sleepiness and activity in heart failure patients with reduced ejection fraction and central sleep-disordered breathing. Sleep Med 34:217-223. https://doi.org/10.1016/j.sleep.2016.11.022

45. Popp R, Kleemann Y, Burger M, Pfeifer M, Arzt M, Budweiser S (2015) Impaired vigilance is associated with erectile dysfunction in 
patients with sleep apnea. THE JOURNAL OF SEXUAL MEDICINE 12(2):405-415. https://doi.org/10.1111/jsm.12789

46. de Backer WA (1995) Central sleep apnoea, pathogenesis and treatment: an overview and perspective. Eur Respir J 8(8):1372-1383. https://doi.org/10.1183/09031936.95.08081372

47. Finan PH, Quartana PJ, Smith MT (2015) The effects of sleep continuity disruption on positive mood and sleep architecture in healthy adults. Sleep 38(11):1735-1742. https://doi.org/10.5665/ sleep. 5154

48. Drake CL, Day R, Hudgel D, Stefadu Y, Parks M, Syron ML, Roth $\mathrm{T}$ (2003) Sleep during titration predicts continuous positive airway pressure compliance. Sleep 26(3):308-311

49. Lewis KE, Seale L, Bartle IE, Watkins AJ, Ebden P (2004) Early predictors of CPAP use for the treatment of obstructive sleep apnea. Sleep 27(1):134-138

50. Collen J, Lettieri C, Kelly W, Roop S (2009) Clinical and polysomnographic predictors of short-term continuous positive airway pressure compliance. Chest 135(3):704-709. https://doi.org/10. 1378/chest.08-2182

51. Lettieri CJ, Collen JF, Eliasson AH, Quast TM (2009) Sedative use during continuous positive airway pressure titration improves subsequent compliance: a randomized, double-blind, placebocontrolled trial. Chest 136(5):1263-1268. https://doi.org/10.1378/ chest.09-0811

52. Olsen S, Smith S, Oei T, Douglas J (2008) Health belief model predicts adherence to CPAP before experience with CPAP. Eur Respir J 32(3):710-717. https://doi.org/10.1183/09031936. 00127507

53. Beecroft J, Zanon S, Lukic D, Hanly P (2003) Oral continuous positive airway pressure for sleep apnea: effectiveness, patient preference, and adherence. Chest 124(6):2200-2208

Publisher's note Springer Nature remains neutral with regard to jurisdictional claims in published maps and institutional affiliations. 